\title{
Preparation of liposome encapsulating angiotensin-I-converting enzyme inhibitory peptides from sunflower protein hydrolysates
}

\author{
PENG LUO ${ }^{1,2}$ and DONG-PING HE ${ }^{1,3}$ \\ ${ }^{1}$ Bioactive Peptides and Functional Foods, College of Food Science and Technology, Huazhong Agricultural University, \\ Wuhan, Hubei 430070; ${ }^{2}$ Bioactive Peptides and Functional Foods, Food College, Shihezi University, Shihezi, \\ Xinjiang 832003; ${ }^{3}$ Bioactive Peptides and Functional Foods, College of Food Science and Engineering, \\ Wuhan Polytechnic University, Wuhan, Hubei 430023, P.R. China
}

Received October 25, 2016; Accepted June 23, 2017

DOI: $10.3892 / \mathrm{mmr} .2018 .8474$

\begin{abstract}
Liposomal angiotensin-I-converting enzyme inhibitory (ACEI) peptides were prepared from sunflower protein hydrolysates by the thin-film ultrasonic method. Response surface methodology (RSM), in combination with fractional factorial designs and central composite design methods were utilized to optimize entrapment efficiency and balance the drug release. We found that the ratio of phospholipids to cholesterol, ultrasound time and the ratio of phospholipids to ACEI peptides were significant factors affecting entrapment efficiency $(\mathrm{P}<0.001)$. Optimal preparation conditions of liposomal-ACEI peptides were the ratio of soybean phospholipids to cholesterol (w/w) of 4.1:1, PEG-2000 dosage (\%) of 4, $\mathrm{NaCl}$ concentration in PBS (mM) of 50, hydration temperature of $45^{\circ} \mathrm{C}$, ultrasound time of $8.05 \mathrm{~min}$ and the ratio of soybean phospholipids to ACEI peptides of 15:1 (w/w). The experimental entrapment efficiency of liposomal-ACEI peptides was $(91.25 \pm 0.182 \%)$. Moreover, the balanced release rate of liposome encapsulated ACEI in phosphate buffer was $77.83 \%$ after $12 \mathrm{~h}$.
\end{abstract}

\section{Introduction}

Synthetic angiotensin-I-converting enzyme (ACE) inhibitory (ACEI) drugs, including captopril, lisinopril, enalapril and ramipril, are effective to treat cardiovascular disease. However, side effects accompany the application of these drugs, including proteinuria, altered sense of taste, allergic skin rashes, cough and drug fever (1). Isolation of effective natural ACEI peptides from diets or crops is an attractive prospect. A series of ACEI peptides derived from food protein sources

Correspondence to: Dr Dong-Ping He, Bioactive Peptides and Functional Foods, College of Food Science and Engineering, Wuhan Polytechnic University, 68 Xuefu South Road, Changqing Garden, Wuhan, Hubei 430023, P.R. China

E-mail: hedongping2351@126.com

Key words: sunflower protein hydrolysates, angiotensin-I-converting enzyme inhibitory peptides, liposome, response surface methodology have been identified, including from fermented milk, cheddar cheeses (2), hen egg white (3), tuna (4), rice (5), soybean (6), peanut meal (7), skate (Okamejei kenojei) skin gelatin (8), flaxseed (9) and pumpkin (10). These ACEI peptides were commonly collected using proteolytic hydrolysis methods or during fermentation processing. Although ACEI peptides from natural food are considered to be safe, they exhibit low efficacy in comparison with synthetic ACEI drugs. Sunflower protein is an important source for ACEI peptides. The procedure for the purification of ACEI peptides derived from sunflower protein, includes the gel filtration chromatography, affinity chromatography and reverse-phase chromatography $(11,12)$. However, it is important to improve the entrapment efficiency and to reduce the release of ACEI peptides.

Liposomes have unique physicochemical properties including the ability to incorporate lipophilic, amphiphilic and/or hydrophilic compounds, and the ability to improve the stability and reduce the toxicity of encapsulated drugs $(13,14)$. Different methodologies are reported to prepare multi-lamellar vesicles, large unilamellar vesicles and small unilamellar vesicles (15). Liposomes formed by thin-film ultrasonic methods have also been widely reported in the literatures (16-19). However, the production of these phospholipids vesicles is poorly reproducible as that ACEI peptides-liposomal experimental set-up is not described in detail.

In this study, it was aimed to optimize the encapsulation conditions for producing liposome ACEI peptides by employing response surface methodology (RSM). In addition, fractional factorial design (FFD) and the central composite design were also used to identify the most important variables for optimizing the encapsulation conditions during the experiments.

\section{Materials and methods}

Materials and chemical reagents. Defatted sunflower meal was supplied by China Oil \& Foodstuffs Corporation (Shihezi Branch, China). Alcalase (ExPASy entry EC 3.4.21.62, Bacillus licheniformis; $2.4 \mathrm{~L}$ ), and flavourzyme (ExPASy entry EC 3.4.11.1; 1,000 mg) were purchased from Novozymes (Bagsvard, Denmark). ACE (ExPASy entry EC 3.4.15.1, rabbit lung; $0.25 \mathrm{U} / \mathrm{ml}$ ) and $\mathrm{N}$-[3-(2-furyl) acryloyl]-L-phenyl-alanylglycylglycine (FAPGG) substrate were purchased from 
Sigma-Aldrich (Merck KGaA, Darmstadt, Germany). Bicinchoninic acid (BCA) protein kit and bovine serum albumin were purchased from Beijing Kangwei Century Biotechnology Co., Ltd. (Beijing, China). Cholesterol, L- $\alpha$-dipalmitoyl phosphatidylcholine (DPPC), phosphatidylcholine (PC), soybean phospholipids (SP), sphingomyelin (SM), 1-myristoyl-2-palmitoyl-sn-glycero-3-phosphatidylcholine (MPPC), and polyethylene glycol (PEG; molecular weight, 2,000) were purchased from Rizhao Jia Qing Trading Co., Ltd. (Rizhao, China). All other chemicals and reagents were of analytical grade.

Preparation of sunflower protein isolates. Defatted sunflower meal flour $(20 \mathrm{~g})$ was extracted by stirring for $1 \mathrm{~h}$ in $200 \mathrm{ml}$ $60 \%$ ethanol aqueous solution. Following vacuum filtration, the residue was washed twice with distilled water and extracted by stirring for $1 \mathrm{~h}$ in $200 \mathrm{ml} \mathrm{NaOH}(0.05 \mathrm{M})$ at room temperature. Following centrifugation at 7,155.2 x g for $20 \mathrm{~min}$, an additional extraction was performed with half the volume of alkaline solution. The $\mathrm{pH}$ of the supernatant was adjusted to the isoelectric point ( $\mathrm{pH} 4.3$ ) of sunflower proteins, and the precipitate formed was recovered by a centrifugation as described above, washed with distilled water and freeze-dried until further use.

Sunflower protein-derived ACEI peptides were prepared according to Villanueva et al (20) and Dadzie et al (21) with modifications: Adjusted hydrolysis $\mathrm{pH}$ for Alcalase from 8 to 8.5 and for Flavourzyme from 7 to 6.5 . In the present study, the fraction of molecular mass $<3 \mathrm{kDa}$ was gained by ultrafiltration following hydrolysis and then added to an open column $(1.6 \times 100 \mathrm{~cm})$ packed with Sephadex G-25 gel Beijing RuiDa HengHui Science and Technology Development Co., Ltd.,(Beijing, China), that had been pre-equilibrated with distilled water.

The ACEI peptides were eluted by distilled water at the speed of $60 \mathrm{ml} / \mathrm{h}$ and the elution peaks were monitored at $220 \mathrm{~nm}$. Those fractions $\left(\mathrm{IC}_{50}, 2.63 \pm 0.08 \mu \mathrm{g} / \mathrm{ml}\right)$ were vacuum freeze-dried and stored at $-20^{\circ} \mathrm{C}$ until use (22).

Preparation of liposome containing ACEI peptides. Liposomal ACEI peptides were prepared by thin-film ultrasonic method as described by Ferreira et al (23) and Cortesi et al (24) with certain modifications. The obtained liposome preparation was incubated at room temperature under continuous stirring (180 $\mathrm{mot} / \mathrm{min}$ ) for $16-18 \mathrm{~h}$ in order to achieve higher entrapment efficiency (25). The preparation of liposome containing ACEI peptides was confirmed by scanning electron microscope (SEM) (JSM-6490LV; JEOL, Ltd., Tokyo, Japan).

Determination of entrapment efficiency. Entrapment efficiency of liposomal ACEI peptides was determined using Centrifree $^{\circledR}$ (EMD Millipore, Billerica, MA, USA) according to previously reported method (26) with certain modifications: The supernatant was analyzed via a BCA Protein Quantitation kit (aforementioned) at $562 \mathrm{~nm}$ to determine the amount of unencapsulated ACEIPs. A standard curve was established with bovine serum albumin.

Liposomal ACEI peptides release assay in vitro. An ACEI peptides release experiment was performed using the dialysis method according to Cortesi et al (24) with slight modification: The adjusted molecular weight of the dialysis tube was reduced from 10,000-12,000 to 8,000-10,000. Analysis of ACEIPs content from by HPLC to BCA Protein Quantitation kit.

FFD. A reduced $\left(2^{6-2}\right)$ factorial design at two levels with resolution IV was selected. The variables were coded according to the following equation: $\mathrm{x}_{\mathrm{i}}=\left(\mathrm{X}_{\mathrm{i}}-\mathrm{X}_{0}\right) / \Delta \mathrm{X}_{\mathrm{i}}$; where $\mathrm{X}_{\mathrm{i}}$ was the coded value of an independent variable, $X_{i}$ was the real value of an independent variable, $\mathrm{X}_{0}$ was the real value of an independent variable at the central point, and $\Delta \mathrm{X}_{\mathrm{i}}$ was the step change value.

Central composite design (CCD). In order to describe the nature of the response surface in the optimum region, a central composite design RSM was performed to examine the effect of the three independent variables $X_{1}$ (phospholipids to cholesterol ratio), $\mathrm{X}_{5}$ (ultrasound time), and $\mathrm{X}_{6}$ (phospholipids to ACEI peptides ratio) at five levels for each variable on the entrapment efficiency.

Statistical analysis. Design expert 8.0.5 software (Stat-Ease, Inc., Minneapolis, MN, USA) was used for analysis of variance (ANOVA) of the mean responses fitted to a second order polynomial to obtain regression equations. Entrapment efficiencies were compared using one-way ANOVA and Bonferroni multiple comparisons test. $\mathrm{P}<0.05$ was considered to indicate a statistically significant difference. The adequacy of the model to navigate the design space of the responses was determined using the coefficient of determination $\left(\mathrm{R}^{2}\right)$ and a lack of fit test. Two-dimensional (2D) contour plots and three-dimensional (3D) response surface plots for the responses were generated for two independent variables while fixing the remaining variable at coded 0 levels. The release profile of liposome containing ACEI peptides and the fitted curve for the percentage ACEI peptides released and release time were constructed by Origin 8.0 (OriginLab Corporation, Northampton, MA, USA).

\section{Results and Discussion}

Effects of phospholipids on preparation of liposome containing ACEI peptides. In order to identify the most appropriate phospholipids for ACEI peptide entrapment, five phospholipids (SP, PC, DPPC, MPPC and SM) were used to prepare the liposome containing ACEI peptides (Fig. 1). The SP formulation had the highest entrapment efficiency $(85.57 \pm 5.68 \%)$, followed by DPPC formulation $(81.24 \pm 9.41 \%)$ and MPPC $(77.31 \pm 10.32 \%)$, and there was no significant difference among them. By contrast, PC and SM formulation exhibited much lower entrapment efficiency (PC, 45.07 $\pm 0.78 \%$; SM, 50.03 $\pm 7.55 \%$ ), which were significantly lower than those of the SP, MPPC and DPPC formulations. These results were consistent with a previous report, in which there were markedly different interactions among peptides and various types of charged liposome (27). Therefore, the SP formulation was chosen to further optimize the entrapment conditions for producing liposomal ACEI peptides because of its higher efficiency and lower cost. Liposomal ACEI peptides were imaged using SEM (Fig. 2).

Screening of preparation conditions for liposomal ACEI peptides using FFD. A $2^{6-2}$ FFD was applied to evaluate the impact of six factors. The entrapment efficiency of liposomal ACEI peptides markedly varied in a range from 40.28-90.91\%. 


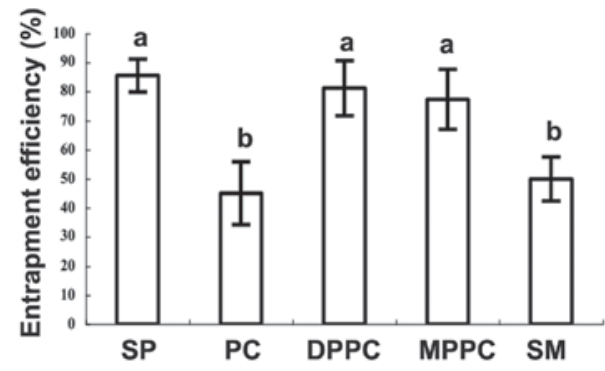

Figure 1. The entrapment efficiency of liposomal angiotensin-I-converting enzyme inhibitory peptides obtained by five different phospholipids formulations. Values are the means of three parallel experiments \pm standard deviation. Statistical significance was calculated using a one-way analysis of variance and Bonferroni multiple comparisons test. Means with different letters $(\mathrm{a}$ and $\mathrm{b})$ indicate significant differences $(\mathrm{P}<0.05)$; means with the same letter are not significantly different to each other.

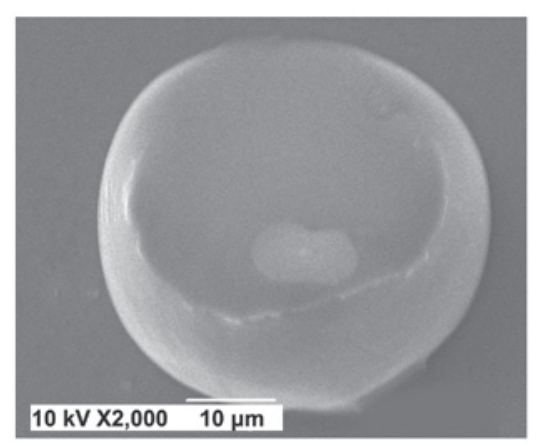

Figure 2. Morphology of the liposomal angiotensin-I-converting enzyme inhibitory peptides imaged by scanning electron microscopy.

The factorial analysis of variances indicated that the ratio of phospholipids to cholesterol $\left(\mathrm{X}_{1}\right)$, ultrasound time $\left(\mathrm{X}_{5}\right)$ and the ratio of phospholipids to ACEI peptides $\left(\mathrm{X}_{6}\right)$ were significant factors $(\mathrm{P}<0.001)$, which affected entrapment efficiency of liposomal ACEI peptides, while PEG-2000 dosage, $\mathrm{NaCl}$ concentration in PBS and hydration temperature were non-significant factors (Table I). In this case, there was significant interaction between $\mathrm{X}_{1}$ and $\mathrm{X}_{6}$, between $\mathrm{X}_{1}$ and $\mathrm{X}_{4}(\mathrm{P}<0.01)$. Using multiple regression analysis, the response variables and the test variables were related by the second-order polynomial equation as follows: $Y_{1}=76.32-4.56 X_{1}-9.84 X_{5}+7.71 X_{6}+3.27$ $\mathrm{X}_{1} \mathrm{X}_{4}-2.66 \mathrm{X}_{1} \mathrm{X}_{5}+3.52 \mathrm{X}_{1} \mathrm{X}_{6}$. The values of $\mathrm{R}^{2}$ and adjusted $\mathrm{R}^{2}$ were 88.76 and $83.58 \%$, respectively, indicating that the model fitted well with the experimental data. The comparable values revealed that non-significant factors were not included in the model. The P-value of lack-of-fit in ANOVA was insignificant for the model at a confidence level of $95 \%(\mathrm{P}=0.0605)$, suggesting that the model represented the data satisfactorily.

$C C D$ and response surface analysis for liposomal ACEI peptides preparation. RSM is a popular and effective method to solve multivariate problems and optimize several responses in many types of experimentation $(28,29)$. Based on the results of FFD analysis, the factors $\left(\mathrm{X}_{1}, \mathrm{X}_{5}\right.$ and $\left.\mathrm{X}_{6}\right)$ were selected for a further optimization of the entrapment efficiency of liposomal ACEI peptides using a Box-Wilson CCD with six replicates at center point for each factor. PEG-2000 dosage $\left(\mathrm{X}_{2}\right), \mathrm{NaCl}$ concentration in PBS $\left(\mathrm{X}_{3}\right)$, hydration temperature $\left(\mathrm{X}_{4}\right)$ were set as $4 \%, 50 \mathrm{mM} / 1$ and $45^{\circ} \mathrm{C}$, respectively. The second-order polynomial equation is as follows: $\mathrm{Y}_{2}=78.34+1.89 \mathrm{X}_{1}-7.46 \mathrm{X}_{5}-9.89$ $\mathrm{X}_{6}-0.13 \mathrm{X}_{1} \mathrm{X}_{5}-2.57 \mathrm{X}_{1} \mathrm{X}_{6}+2.79 \mathrm{X}_{5} \mathrm{X}_{6}-4.06 \mathrm{X}_{1}^{2}-13.29 \mathrm{X}_{5}^{2}-0.61$ $\mathrm{X}_{6}^{2}$; where $\mathrm{Y}_{2}$ is the predicted entrapment efficiency in real value, and $X_{1}, X_{5}$ and $X_{6}$ are the coded values of independent variable the ratio of phospholipids to cholesterol, ultrasound time and the ratio of phospholipids to ACEI peptides, respectively.

Table II presents results of the second-order response surface model in the form of ANOVA. The Fisher's F-test with a very low probability value $[(\mathrm{Prob}>\mathrm{F})<0.0001]$ indicated the model was highly significant. The model fitted the data with an acceptable determination coefficient $\left(\mathrm{R}^{2}=0.9761\right)$ and no significant lack-of-fit ( $\mathrm{P}=0.1491)$, which indicated that the sample variation of $97.61 \%$ could be attributed to the independent variables, and the model did not explain only $2.39 \%$ of the total variations. The adjusted determination coefficient $\left(\mathrm{R}^{2}=0.9546\right)$ was also satisfactory to confirm the significance of the model. Meanwhile, the low value of coefficient of variation $(\mathrm{CV}=5.26 \%)$ implicated accuracy and reliability of the experiments.

The regression analysis showed that the ultrasound time $\left(\mathrm{X}_{5}\right)$ and the ratio of phospholipids to ACEI peptides $\left(\mathrm{X}_{6}\right)$ had a very significant linear effect on entrapment efficiency. Meanwhile the ultrasound time $\left(\mathrm{X}_{5}\right)$ and the ratio of cholesterol to phospholipids $\left(\mathrm{X}_{1}\right)$ exhibited a significant quadratic effect $(\mathrm{P}<0.01)$. In addition, an interaction between the ultrasound time and the ratio of phospholipids to ACEI peptides for the entrapment efficiency $(\mathrm{P}<0.05)$ was also observed. The linear effects of $X_{1}$, quadratic effect of $X_{6}{ }^{2}$ and interaction effects of $\mathrm{X}_{1} \mathrm{X}_{5}$ and $\mathrm{X}_{1} \mathrm{X}_{6}$ were demonstrated to be non-significant on the entrapment efficiency of liposomal ACEI peptides.

To illustrate the interaction of the ratio of phospholipids to cholesterol, ultrasound time and ratio of phospholipids to ACEI peptides and to efficiently optimize the variables, 3D response surface plots and the 2D contour plots were obtained. As shown in Fig. 3, a visual interpretation of the interactions between the two independent variables on the entrapment efficiency was observed, while the third variable was held at zero level. The circular contour plots of response surfaces suggest that the interaction is negligible among the corresponding variables. An elliptical or saddle nature of the contour plots indicates the significance of the interactions between the corresponding variables. In the case of saddle contour plots, the optimum values are obtained at the point of intersection of lines, which are formed by joining the locus (30).

Fig. 3A and B demonstrate that entrapment efficiency of liposomal ACEI peptides was increased with the increase of ultrasound time from 5 to $10 \mathrm{~min}$, while it was decreased when the ultrasound time was $>10 \mathrm{~min}$. The result was similar to a previous publication (31). The entrapment efficiency was increased with the ratio of phospholipids to cholesterol until a peak was detected at $\sim 3: 1$ (w:w). In Fig. 3B, the saddle contour plots demonstrated that interactions between phospholipids to cholesterol ratio and phospholipids to ACEI peptides ratio also reached optimum levels. Fig. $3 \mathrm{C}$ shows that the entrapment efficiency of liposomal ACEI peptides increased with the decrease of the ratio of phospholipids to ACEI peptides from 25:1 to $15: 1$ (w:w) when the ratio of phospholipids to cholesterol was set. There was a saddle in the contour plot (Fig. 3C), indicating the significance of interactions between ultrasound time and the ratio of phospholipids to ACEI peptides. 
Table I. Analysis of variances results of fractional factorial designs for entrapment efficiency ( $\mathrm{Y}_{1}$ ) of liposomal angiotensin-Iconverting enzyme inhibitory peptides.

\begin{tabular}{lrrrrr}
\hline Source & Sum of squares & Degrees of freedom & Mean square & F-value & P-value (Prob $>$ F) \\
\hline Model & $3,314.86$ & 6 & 552.48 & 43.82 & $<0.0001$ \\
$\mathrm{X}_{1}$ & 332.70 & 1 & 332.70 & 26.39 & 0.0002 \\
$\mathrm{X}_{5}$ & $1,550.39$ & 1 & $1,550.39$ & 122.97 & $<0.0001$ \\
$\mathrm{X}_{6}$ & 950.18 & 1 & 950.18 & 75.36 & $<0.0001$ \\
$\mathrm{X}_{1} \mathrm{X}_{4}$ & 170.69 & 1 & 170.69 & 13.54 & 0.0032 \\
$\mathrm{X}_{1} \mathrm{X}_{5}$ & 113.21 & 1 & 113.21 & 8.98 & 0.0111 \\
$\mathrm{X}_{1} \mathrm{X}_{6}$ & 197.68 & 1 & 197.68 & 15.68 & 0.0019 \\
Curvature & 268.28 & 1 & 268.28 & 21.28 & 0.0006 \\
Residual & 151.29 & 12 & 12.61 & & 0.0605 \\
Lack of fit & 144.99 & 9 & 16.11 & 7.66 & \\
Pure error & 6.31 & 3 & 2.10 & & \\
Corrected total & $3,734.43$ & 19 & & & \\
\hline
\end{tabular}

Table II. Analysis of variances for the entrapment efficiency $\left(\mathrm{Y}_{2}\right)$ in coded level variables.

\begin{tabular}{lrrrrr}
\hline Source & Sum of squares & Degrees of freedom & Mean square & F-value & P-value (Prob $>$ F) \\
\hline Model & $4,927.74$ & 9 & 547.53 & 45.35 & $<0.0001$ \\
$\mathrm{X}_{1}$ & 48.58 & 1 & 48.58 & 4.02 & 0.0727 \\
$\mathrm{X}_{5}$ & 759.19 & 1 & 759.19 & 62.88 & $<0.0001$ \\
$\mathrm{X}_{6}$ & $1,337.10$ & 1 & $1,337.10$ & 110.74 & $<0.0001$ \\
$\mathrm{X}_{1} \mathrm{X}_{5}$ & 0.13 & 1 & 0.13 & 0.01 & 0.9192 \\
$\mathrm{X}_{1} \mathrm{X}_{6}$ & 52.75 & 1 & 52.75 & 4.37 & 0.0631 \\
$\mathrm{X}_{5} \mathrm{X}_{6}$ & 62.49 & 1 & 62.49 & 5.17 & 0.0462 \\
$\mathrm{X}_{1}{ }^{2}$ & 238.00 & 1 & 238.00 & 19.71 & 0.0013 \\
$\mathrm{X}_{5}{ }^{2}$ & $2,544.30$ & 1 & $2,544.30$ & 210.72 & $<0.0001$ \\
$\mathrm{X}_{6}{ }^{2}$ & 5.29 & 1 & 5.29 & 0.44 & 0.5231 \\
Residual & 120.74 & 10 & 12.07 & & 0.1491 \\
Lack of fit & 88.18 & 5 & 17.64 & 2.71 & \\
Pure error & 32.56 & 5 & 6.51 & & \\
Corrected total & $5,048.48$ & 19 & & &
\end{tabular}

Validation of the experimental design. The optimum conditions for the entrapment efficiency of liposomal ACEI peptides were calculated based on the data obtained using the 'response optimizer' option of Design-Expert software. The optimal values of each variable in coded units were as follows: $\mathrm{X}_{1}=0.55, \mathrm{X}_{5}=-0.39$ and $\mathrm{X}_{6}=-1$. Their actual values were 4.1:1 (w:w) of phospholipids to cholesterol ratio $\left(\mathrm{X}_{1}\right), 8.05 \mathrm{~min}$ of ultrasound time $\left(\mathrm{X}_{5}\right)$ and 15:1 (w:w) of phospholipids to ACEI peptides ratio $\left(\mathrm{X}_{6}\right)$, respectively. The model predicted that the entrapment efficiency of liposomal ACEI peptides could reach $90.86 \%$ by using the above optimized condition of the variables. The experiments were repeated three times to validate the suitability of the model equations. The entrapment efficiency $(91.25 \pm 0.182 \%, \mathrm{n}=3)$ was obtained from the real experiments, indicating validation of the RSM model.

ACEI peptides release assay. The liposomal ACEI peptides were subjected to release experiments in vitro in order to provide information about the efficiency of release of ACEI peptides from liposome. As reported in Fig. 4, the percentage of ACEI peptides released in phosphate buffer was $95.74 \%$ after $12 \mathrm{~h}$, whereas it was $77.83 \%$ after $12 \mathrm{~h}$ for liposomal ACEI peptides. The release of liposome-entrapped ACEI peptides was significantly delayed compared with ACEI peptides in phosphate buffer. Furthermore, the fitted equation of the percentage of ACEI peptides released vs. release time was calculated based on different release models (zero-order dynamic, one-order dynamic, Korsmeyer-Peppas, Higuchi, logistic) $(32,33)$. The logistic model and one-order dynamic model were well-fitted with the release percentage of ACEI peptides (adjusted $\mathrm{R}^{2}$ of 0.9883 and 0.9841 , respectively).

In conclusion, liposomal ACEI peptides derived from sunflower protein hydrolysates were prepared with the aims of improving entrapment efficiency and sustaining release. The ratio of phospholipids to cholesterol, ultrasound time and the ratio of phospholipids to ACEIPs were notable factors affecting entrapment efficiency. Under optimal experimental conditions, the 

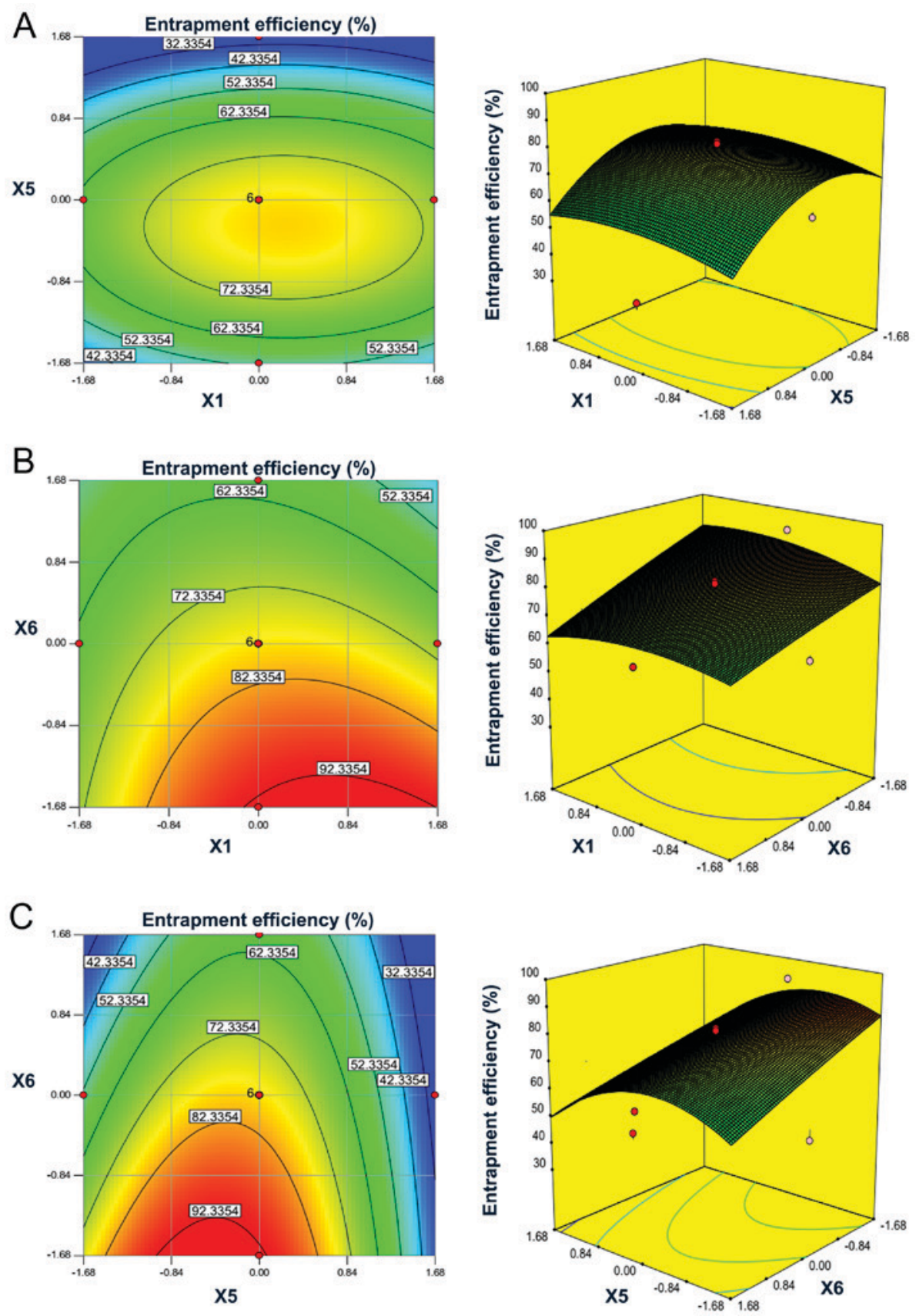

Figure 3. 2D contour plots and 3D response surface curve for the interactive effects of variables on the entrapment efficiency of liposomal ACEIPs. (A) Pphospholipids to cholesterol ratio and ultrasound time; (B) phospholipids to cholesterol ratio and phospholipids to ACEIPs ratio; (C) ultrasound time and phospholipids to ACEIPs ratio. ACEIPs, angiotensin-I-converting enzyme inhibitory peptides.

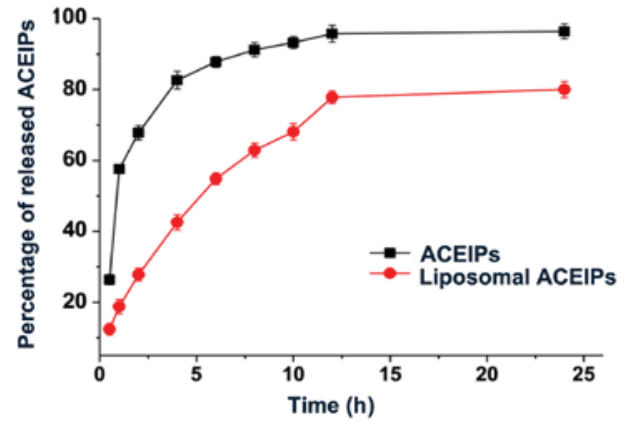

Figure 4. Release profile of ACEIPs encapsulated in liposome. The releases were determined using the dialysis method. For comparison, ACEIPs release in PBS is also presented. ACEIPs, angiotensin-I-converting enzyme inhibitory peptides. entrapment efficiency of liposomal ACEIPs was $91.25 \pm 0.182 \%$. The percentage of released of liposomal ACEIPs was reduced by $17.91 \%$ compared with ACEIPs in phosphate buffer after $12 \mathrm{~h}$. However, there are some limitations of the present study. The release of liposome-entrapped ACEIPs in simulated gastric fluid and simulated intestinal fluid was not investigated, and the stability of liposomes was also not analyzed under long durations of preservation; further investigation is required.

\section{Acknowledgements}

The present study was partially supported by a grant of College Students' Innovative Training Program of China (grant no. 201410759048). 


\section{References}

1. Ogihara T, Mikami H, Katahira K and Otsuka A: Comparative study of the effects of three angiotensin converting enzyme inhibitors on the cough reflex. Am J Hypertens 4: 46S-51S, 1991

2. Ong L and Shah NP: Influence of probiotic Lactobacillus acidophilus and L. helveticus on proteolysis, organic acid profiles and ACE-inhibitory activity of cheddar cheeses ripened at 4,8 and 12 degrees C. J food sci 73: M111-M120, 2008.

3. Ong L and Shah NP: Release and identification of angiotensin-converting enzyme-inhibitory peptides as influenced by ripening temperatures and probiotic adjuncts in cheddar cheeses. LWT-Food Sci Technol 41: 1555-1566, 2008.

4. Hwang JS: Impact of processing on stability of angiotensin Iconverting enzyme (ACE) inhibitory peptides obtained from tuna cooking juice. Food Res Int 43: 902-906, 2010.

5. Chen J, Liu S, Ye R, Cai G, Ji B and Wu Y: Angiotensin-I converting enzyme (ACE) inhibitory tripeptides from rice protein hydrolysate: Purification and characterization. J Functional Foods 5: 1684-1692, 2013.

6. Gu Y and Wu J: LC-MS/MS coupled with QSAR modeling in characterising of angiotensin I-converting enzyme inhibitory peptides from soybean proteins. Food Chem 141: 2682-2690 2013.

7. White BL, Sanders TH and Davis JP: Potential ACE-inhibitory activity and nanoLC-MS/MS sequencing of peptides derived from aflatoxin contaminated peanut meal. LWT-Food Sci Technol 56: 537-542, 2014

8. Ngo DH,Ryu B and Kim SK: Active peptides from skate (Okamejei kenojei) skin gelatin diminish angiotensin-I converting enzyme activity and intracellular free radical-mediated oxidation. Food Chem 143: 246-255, 2014.

9. Udenigwe CC, Lin YS, Hou WC and Aluko RE: Kinetics of the inhibition of renin and angiotensin I-converting enzyme by flaxseed protein hydrolysate fractions. J Functional Foods 1: 199-207, 2009

10. Vaštag Ž, Popović L, Popović S, Krimer V and Peričin D: Production of enzymatic hydrolysates with antioxidant and angiotensin-I converting enzyme inhibitory activity from pumpkin oil cake protein isolate. Food Chem 124: 1316-1321, 2011.

11. Megias C, del Mar Yust M, Pedroche J, Lquari H, Girón-Calle J, Alaiz M, Millán F and Vioque J: Purification of an ACE inhibitory peptide after hydrolysis of sunflower (Helianthus annuus L.) protein isolates. J agric food chem 52: 1928-1932, 2004.

12. Megias C, Pedroche J, Yust Mdel M, Alaiz M, Girón-Calle J, Millan F and Vioque J: Affinity purification of angiotensin converting enzyme inhibitory peptides using immobilized ACE. J Agric Food Chem 54: 7120-7124, 2006

13. Du B, Li Y, Li X, A Y, Chen C and Zhang Z: Preparation, characterization and in vivo evaluation of 2-methoxyestradiol-loaded liposomes. Int J Pharm 384: 140-147, 2010.

14. Milla P, Dosio F and Cattel L: PEGylation of proteins and liposomes: A powerful and flexible strategy to improve the drug delivery. Current Drug Metab 13: 105-119, 2012.

15. Vemuri S and Rhodes CT: Preparation and characterization of liposomes as therapeutic delivery systems: A review. Pharm Acta Helv 70: 95-111, 1995.

16. Andrade CA, Correia MT, Coelho LC, Nascimento SC and Santos-Magalhaes NS: Antitumor activity of Cratylia mollis lectin encapsulated into liposomes. Int J Pharm 278: 435-445, 2004.
17. Pereira-Lachataignerais J, Pons R, Panizza P, Courbin L, Rouch J and Lopez O: Study and formation of vesicle systems with low polydispersity index by ultrasound method. Chem Phys Lipids 140: 88-97, 2006.

18. Silva R, Little C, Ferreira H and Cavaco-Paulo A: Incorporation of peptides in phospholipid aggregates using ultrasound. Ultrason Sonochem 15: 1026-1032, 2008.

19. Shaw GJ, Meunier JM, Huang SL, Lindsell CJ, McPherson DD and Holland CK: Ultrasound-enhanced thrombolysis with tPA-loaded echogenic liposomes. Thromb Res 124: 306-310, 2009.

20. Villanueva A, Vioque J, Sánchez-Vioque R, Clemente A, Pedroche J, Bautista J and Millán F: Peptide characteristics of sunflower protein hydrolysates. J Amer Oil Chem Soc 76: 1455-1460, 1999

21. Dadzie R, Ma H, Abano E, Qu W and Mao S: Optimization of process conditions for production of angiotensin I-converting enzyme (ACE) inhibitory peptides from vital wheat gluten using response surface methodology. Food Sci Biotechnol 22: 1531-1537, 2013.

22. Yu Z, Liu B, Zhao W, Yin Y, Liu J and Chen F: Primary and secondary structure of novel ACE-inhibitory peptides from egg white protein. Food Chem 133: 315-322, 2012.

23. Ferreira H, Lúcio M, Lima JL, Matos C and Reis S: Interaction of clonixin with EPC liposomes used as membrane models. J Pharm Sci 94: 1277-1287, 2005.

24. Cortesi R, Argnani R, Esposito E, Dalpiaz A, Scatturin A, Bortolotti F, Lufino M, Guerrini R, Cavicchioni G, Incorvaia C, et al: Cationic liposomes as potential carriers for ocular administration of peptides with anti-herpetic activity. Int J Pharm 317: 90-100, 2006

25. Jeong JM, Chung YC and Hwang JH: Enhanced adjuvantic property of polymerized liposome as compared to a phospholipid liposome. J Biotechnol 94: 255-263, 2002.

26. Huang YZ, Gao JQ, Liang WQ and Nakagawa S: Preparation and characterization of liposomes encapsulating chitosan nanoparticles. Biol Pharm Bull 28: 387-390, 2005.

27. Moeller EH, Holst B, Nielsen LH, Pedersen PS and Østergaard J: Stability, liposome interaction and in vivo pharmacology of ghrelin in liposomal suspensions. Int J Pharm 390: 13-18, 2010.

28. McDonald DB, Grantham WJ, Tabor WL and Murphy MJ: Global and local optimization using radial basis function response surface models. Applied Math Model 31: 2095-2110, 2007.

29. Dong X, Pan R, Zou S, He M and Wang C: Oxidative degradation of the sulfated polysaccharide isolated from sea cucumber Holothuria nobilis. Process Biochem 50: 294-301, 2015.

30. Murthy MSRC, Swaminathan T, Rakshit SK and Kosugi Y: Statistical optimization of lipase catalyzed hydrolysis of methyloleate by response surface methodology. Bio Eng 22: 35-39, 2000.

31. Chang L and Zhao Y: Studies on preparation and properties of Vc nano liposomes. J Appli Sci Eng Innov 1: 237-240, 2014.

32. Nounou MM, El-Khordagui LK, Khalafallah NA and Khalil SA: In vitro release of hydrophilic and hydrophobic drugs from liposomal dispersions and gels. Acta Pharm 56: 311-324, 2006.

33. Boyd BJ, Whittaker DV, Khoo SM and Davey G: Lyotropic liquid crystalline phases formed from glycerate surfactants as sustained release drug delivery systems. Int J Pharm 309: 218-226, 2006. 